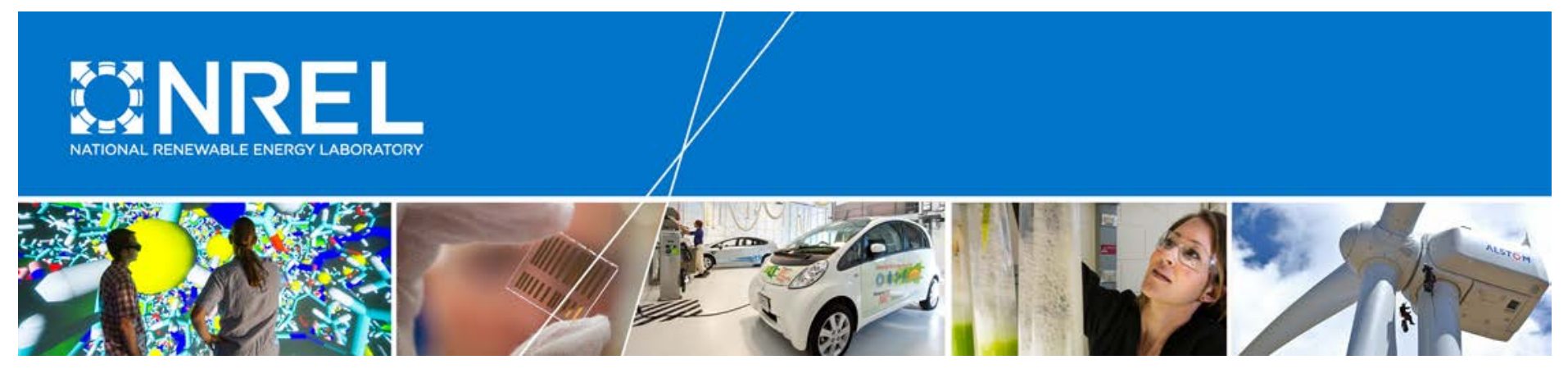

\title{
Design of a Modular E-Core Flux Concentrating Axial Flux Machine
}

\section{Preprint}

Tausif Husain, ${ }^{1}$ Yilmaz Sozer, ${ }^{1}$ Iqbal Husain, ${ }^{2}$ and Eduard Muljadi ${ }^{3}$

${ }^{1}$ University of Akron

${ }^{2}$ North Carolina State University

${ }^{3}$ National Renewable Energy Laboratory

To be presented at the IEEE Energy Conversion Congress and Exposition

Montreal, Canada

September 20-24, 2015

NREL is a national laboratory of the U.S. Department of Energy Office of Energy Efficiency \& Renewable Energy

Operated by the Alliance for Sustainable Energy, LLC

This report is available at no cost from the National Renewable Energy Laboratory (NREL) at www.nrel.gov/publications.

\section{Conference Paper}

NREL/CP-5D00-64748

August 2015

Contract No. DE-AC36-08GO28308 


\section{NOTICE}

The submitted manuscript has been offered by an employee of the Alliance for Sustainable Energy, LLC (Alliance), a contractor of the US Government under Contract No. DE-AC36-08GO28308. Accordingly, the US Government and Alliance retain a nonexclusive royalty-free license to publish or reproduce the published form of this contribution, or allow others to do so, for US Government purposes.

This report was prepared as an account of work sponsored by an agency of the United States government. Neither the United States government nor any agency thereof, nor any of their employees, makes any warranty, express or implied, or assumes any legal liability or responsibility for the accuracy, completeness, or usefulness of any information, apparatus, product, or process disclosed, or represents that its use would not infringe privately owned rights. Reference herein to any specific commercial product, process, or service by trade name, trademark, manufacturer, or otherwise does not necessarily constitute or imply its endorsement, recommendation, or favoring by the United States government or any agency thereof. The views and opinions of authors expressed herein do not necessarily state or reflect those of the United States government or any agency thereof.

This report is available at no cost from the National Renewable Energy Laboratory (NREL) at www.nrel.gov/publications.

Available electronically at SciTech Connect http:/www.osti.gov/scitech

Available for a processing fee to U.S. Department of Energy and its contractors, in paper, from:

U.S. Department of Energy

Office of Scientific and Technical Information

P.O. Box 62

Oak Ridge, TN 37831-0062

OSTI http://www.osti.gov

Phone: 865.576.8401

Fax: 865.576.5728

Email: reports@osti.gov

Available for sale to the public, in paper, from:

U.S. Department of Commerce

National Technical Information Service

5301 Shawnee Road

Alexandria, VA 22312

NTIS http://www.ntis.gov

Phone: 800.553 .6847 or 703.605 .6000

Fax: 703.605.6900

Email: orders@ntis.gov 


\section{Design of a Modular E-Core Flux Concentrating Axial Flux Machine}

\author{
Tausif Husain ${ }^{(1)}$ \\ (1)ECE Department \\ The University of Akron \\ Akron, USA
}

\author{
Yilmaz Sozer ${ }^{(1)}$ \\ (2) ECE Department \\ North Carolina State University \\ Raleigh, USA
}

Iqbal Husain ${ }^{(2)}$

\author{
Eduard Muljadi $^{(3)}$ \\ (3) National Renewable Energy \\ Laboratory \\ Golden, CO, USA
}

\begin{abstract}
In this paper a novel E-Core axial flux machine is proposed. The machine has a double stator-single rotor configuration with flux concentrating ferrite magnets, and pole windings across each leg of an E-Core stator. E-Core stators with the proposed flux-concentrating rotor arrangement result in better magnet utilization and higher torque density. The machine also has a modular structure facilitating simpler construction. This paper presents a single phase and a threephase version of the E-Core machine. Case study for a $1.1 \mathrm{~kW}$, $400 \mathrm{rpm}$ machine for both the single phase and three-phase axial flux machine is presented. The results are verified through 3D finite element analysis.
\end{abstract}

\section{INTRODUCTION}

Development of alternative machine topologies with reduced rare earth or no permanent magnets is of interest for cost sensitive applications. Reluctance machines and machines with lower cost ferrite magnets are two such alternatives which can attain a torque density similar to rare earth PM machines with radial flux machine (RFM) configurations but require challenging design innovations [1]. On the other hand, axial flux machines (AFM) and transverse flux machines (TFM) offer a higher torque density in comparison to RFM [2-4]. This paper proposes a modular E-Core based axial flux machine with flux concentrating ferrite magnets.

The uses of E-cores in the stator result in a modular structure. Modularity in Switched Flux Permanent Magnet Machines (SFPM) with E and C-cores has been reported in the literature [5-8]. Rotor modularity was also achieved in [9] by the use of segmented rotors, which resulted in lower iron losses. Large permanent magnet machines with flux concentrating structures were presented in [10-12]. However, all these machines are RFMs in nature. Modularity in AFMs was presented in [13] where a C-core with ring windings were employed. The machine has embedded magnets into the in the rotor core and a simple modular structure. However, the machine could only be multiphase in nature by stacking multiple single-phase machines. Modularity in TFMs with E-core stators was proposed in TFM [14, 15]. The machines are reluctance machines and use ring windings. TFMs generally result in high torque density due to transverse flux paths.

In electric machines, it is necessary for the magnetic flux and the torque producing current to be perpendicular to each other. Thus the flux lines are either parallel (longitudinal) or perpendicular (transversal) to the moving direction of the rotor. These can be established through four winding variants, Gramme-, Drum-, Pole- and Ring- windings [16]. In this paper, the flux lines of the proposed machine are transversal in the stator back iron, which is achieved by pole windings.

In machines with rotor PMs, flux-concentrating structures have a better performance in terms of torque density [13, 17]. The flux concentration concept enables a higher air gap flux density with magnets having a low remnant flux density. The use of C-cores in [13] resulted in incomplete magnet utilization. A Z-core with intermediate poles and ring windings were investigated in [9]. The use of Z-core intermediate poles would improve the magnet utilization in [13]. The machine suffer from high leakage and complete magnet utilization was still not achieved.

The proposed E-core machine is a double-stator, singlerotor machine with ferrite magnets arranged in flux concentrating manner in the rotor. E-cores with pole windings are used to obtain complete magnet utilization. This allows the stator to be modular. The proposed machine is different from standard AFM in that it has transverse flux flow in the stator back iron compared to radial flux flow in the back iron in AFM [4]. Multi-phase versions of the proposed machine can be attained on a single stack due to the use of pole windings. Design of both single-phase and three- phase E-Core AFM is presented in the paper. The design is based on a case study $1.1 \mathrm{~kW}, 400 \mathrm{rpm}$ machine. A crude optimization with RFMs based on the same stator outer diameters for comparison is also presented. 


\section{PROPOSED E-CORE AXIAL FLUX MACHINE}

\section{A. Proposed Machine Structure}

A 2D view of one pole is shown in Fig. 1. The sandwiched magnets between the rotor cores redirect the flux direction produced by the magnet. The flux-focusing factor can be adjusted in the axial direction by the height of the rotor core (Hry) and it is not confined to the diameter of the air gap. The magnet directions are arranged to have the north poles of the two magnets either pointing towards each other or pointing away from each other. E-core stators with pole windings are employed to use the rotor cores at the two sides. Pole windings facilitate the short flux path shown in Fig 1. The rotor is attached to the rotor shaft and the stator windings are located at both sides of the rotor shown in Fig 2 .

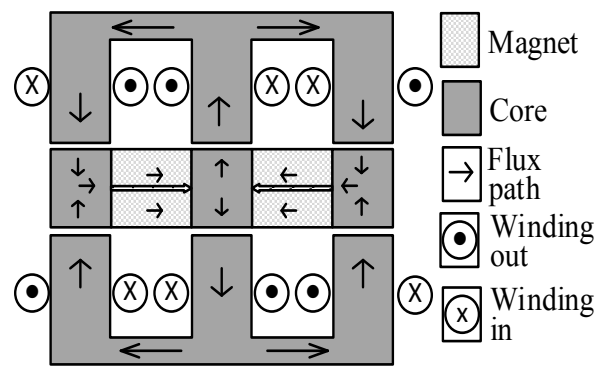

Figure 1: 2-D Side view of one pole of the proposed AFM.

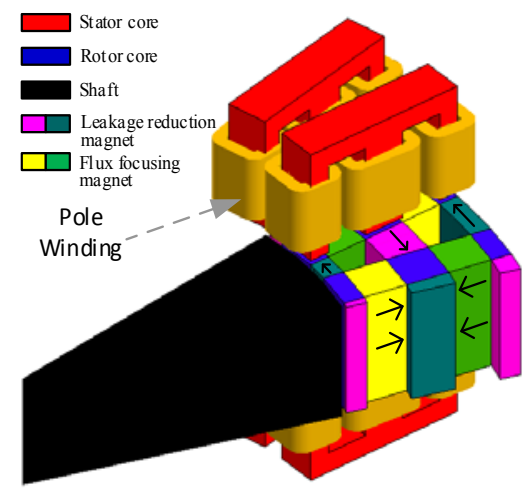

Figure 2: Isometric view of one pole.

The magnetic polarity of the magnets is focused towards the middle rotor core. The coils are arranged so that there is clockwise flux flow in the top right window and anticlockwise in the top left. The flux flow on the other side is the mirror of this. Hence, the flux is leaving through the middle core and entering through the outer and inner rotor cores. More magnets for leakage flux reduction can also be used. These leakage flux reduction magnets can act as flux guides to prevent pole-to-pole leakage.

\section{B. Design Considerations}

The effect of different geometrical parameters on the machine performance is presented in this section. The key geometric parameters of the rotor and stator are presented in Fig. 3.

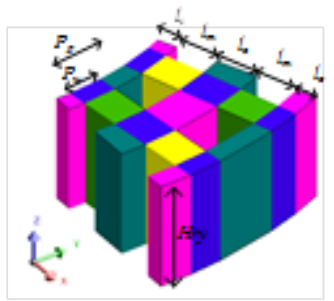

(a) Rotor (excluding stator)

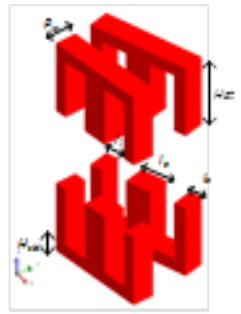

(b) Stator
Figure 3: Geometric parameters of the proposed machine.

A single phase machine is designed according to the case study specification and selected as the base design. The machine dimensions are tabulated in Table 1.

TABLE 1: MAIN DESIGN PARAMETERS OF THE CASE STUDY MACHINE

\begin{tabular}{cc}
\hline \hline Machine Parameter & Value \\
\hline \hline Stator pole & 30 \\
Rotor pole & 30 \\
Air gap $(g)$ & $1 \mathrm{~mm}$ \\
Magnet Type & Ferrite with $0.4 \mathrm{~T}(\mathrm{Br})$ \\
Magnet length $\left(l_{m}\right)$ & $10 \mathrm{~mm}$ \\
Shaft length & $73 \mathrm{~mm}$ \\
Inner core length $\left(l_{i}\right)$ & $4.75 \mathrm{~mm}$ \\
Center core length $\left(l_{c}\right)$ & $10 \mathrm{~mm}$ \\
Outer core length $\left(l_{o}\right)$ & $4.75 \mathrm{~mm}$ \\
Pole width $\left(P_{w}\right)$ & $8.25 \mathrm{~mm}$ \\
Pole Pitch $\left(P_{p}\right)$ & $15.289 \mathrm{~mm}$ \\
Height of rotor $(H r y)$ & $26 \mathrm{~mm}$ \\
Height of stator teeth $(H s t)$ & $21.25 \mathrm{~mm}$ \\
Stator back iron $(\mathrm{Hsbi})$ & $4.75 \mathrm{~mm}$ \\
Number of turns & 6 \\
Rated Current & $72 \mathrm{~A} \mathrm{peak}$ \\
DC bus voltage & $48 \mathrm{~V}$ \\
Rated Speed & $400 \mathrm{rpm}$ \\
Rated Current density & $5.4 \mathrm{~A} / \mathrm{mm}$ \\
\hline \hline
\end{tabular}

The airgap flux of the proposed machine is in the axial direction. The general sizing equation for estimating the power output $\left(P_{o}\right)$ for this E-core AFM is [19]:

$$
P_{o}=\frac{\pi}{2} K_{e} K_{p} K_{i} \eta B_{g} A\left(\frac{f}{P}\right)\left(1-\lambda^{2}\right)\left(\frac{1+\lambda}{2}\right) D_{o}^{3}
$$

where $K_{e}$ is the back-emf factor, $K_{i}$ is the current wave form factor, $K_{p}$ is the power waveform factor, $\eta$ is the efficiency, $B_{g}$ is the airgap flux density, $A$ is the electrical loading, $f$ is converter frequency, $P$ is the pole number, $D_{o}$ is the rotor outer diameter. $\lambda$ is the ratio of rotor inner diameter to outer diameter given as:

$$
\lambda=\frac{D_{i}}{D_{o}}
$$

According to Eqn. 1, the machine power level is the most sensitive to the outer diameter. As the shaft length increases, the outer diameter and as a result the machine's no load rms voltage and average torque increases as shown in Fig. 4. The rate of change of average torque is the most when $\lambda$ is 
between 0.56 and 0.66 which is in agreement with the published literature [19-21].

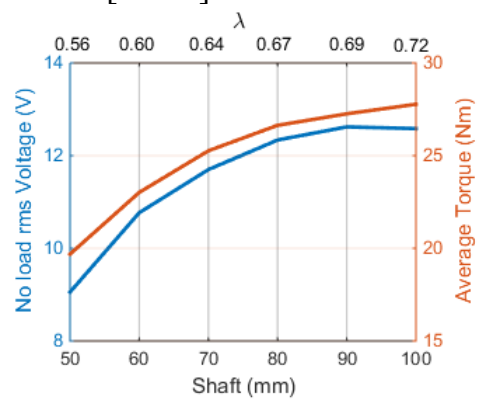

Figure 4: Effect of shaft length on machine performance.

The flux-focusing factor helps determine the airgap flux density of the machine. The focusing factor is defined as:

$$
K_{f}=\frac{H r y}{l_{c}}
$$

The relation between the flux-focusing factor and the airgap flux density is be given by:

$$
B_{g}=k_{l} k_{f} B_{m}
$$

where, $B_{m}$ is the working flux of the PMs and $k_{l}$ is the leakage factor of the machine. The $B_{m}$ in this machine is found from a simple magnetic circuit solution of Fig 1. The value of $k_{l}$ is picked based on differences between FEA and analytical airgap flux density calculation for different pole numbers. The effect of increasing the focusing factor $K_{f}$ is shown in Fig. 5.

The back-emf factor $K_{e}$ can be determined from the airgap flux in the center pole of the machine and is given by:

$$
K_{e}=\frac{k_{\text {fring }} N P^{2} B_{g} A_{c}}{\pi}
$$

where, the $k_{\text {fring }}$ is a factor considering the increase in total flux due to fringing effects. $N$ is the number of turns in a slot, $P$ is the number of poles and $A_{c}$ is the area under the center pole.

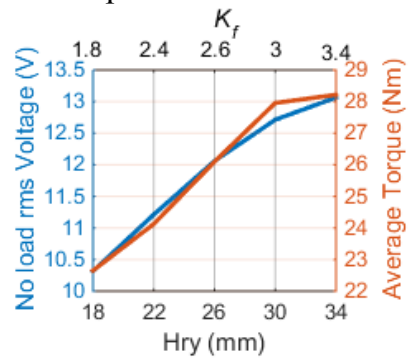

(a) No load voltage and torque.

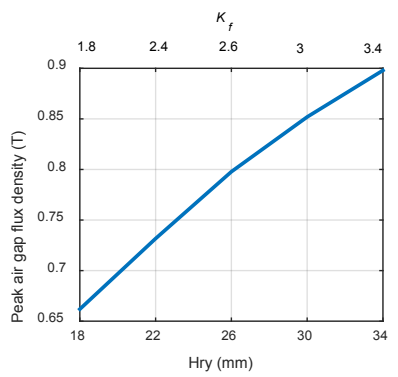

(b) Air gap flux density.
Figure 5: Effect of Hry on machine performance.

The machine can be designed with near sinusoidal back-emf voltages; thus, $K_{i}$ is selected as $\sqrt{2}$ and $K_{p}$ as 0.5 . The core length terms $\left(l_{i}, l_{c}\right.$ and $\left.l_{o}\right)$ are selected based on the flux saturation levels in the E-core teeths. The flux through the center teeth is almost double to that of the inner and outer teeths. Thus, the length of the center teeth is kept at double. The electric loading $A$ is given by:

$$
A_{m}=P \frac{\sqrt{2} I_{a} N}{\pi D_{g}}
$$

where, $I_{a}$ is the stator armature current, $N$ is the number of poles, $D_{g}$ is the average air gap diameter and $P$ is the number of poles. An increase in the number of poles leads to higher electric loading. However, the stator MMF needs to be decreased for ensuring the same current density due to lower winding space. This machine has three air gaps and two stators; therefore, Eqn. 1 is modified to take into account the three air gaps and the two stator sides. The sizing Eqn. for a single phase E-core AFM can thus be expressed as:

$$
P_{o}=\pi K_{e} K_{p} K_{i} \eta \sum_{k=1}^{3}\left(B_{g k} A\left(\frac{f}{P}\right)\left(1-\lambda^{2}\right)\left(\frac{1+\lambda}{2}\right) D_{o}^{3}\right)
$$

where, the subscript $k$ is for the three air gaps.

\section{Material considerations}

Another important factor in the design of this machine is the selection of materials. The first consideration is whether to use soft magnetic composites (SMC) or laminated steel for the rotor and stator cores. SMC have isotropic magnetic properties and can be molded into complex shapes facilitating 3-D flux paths. However, SMC has a lower magnetic permeability and lower saturation flux density compared to laminated steels as presented in Fig. 6a.

Most laminated cores are made of non-oriented silicon steel sheets where individual steel sheets are stacked together to form the core to help reduce the eddy current losses.

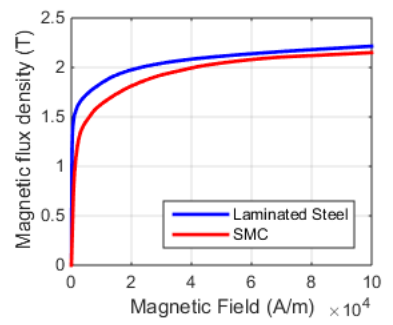

(a) Core material

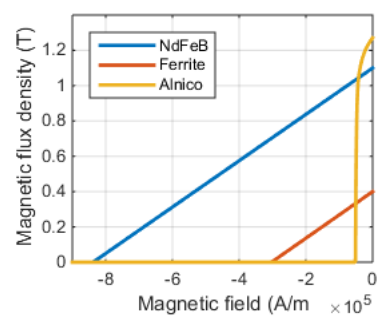

(b) Magnet material Figure 6: (a) BH curve of laminated steel and SMC used in study. (b) Magnetic characteristic of permanent magnets.

In rotary electric machines, the stator and rotor segments are arc shaped. An example of the stator core with arc-segments is shown in Fig 7a. The difficulty with the arc segments in the E-core AFM is its fabrication. The arc shape is very difficult to obtain with laminated steels, and SMC material is the only option. However, a rectangular segment for the stator and rotor cores is another option where laminated steel can be used. The proposed machine with no arcelements is shown in Fig. $7 \mathrm{~b}$. The case study $1.1 \mathrm{~kW}, 400$ rpm $48 \mathrm{~V}$ machine is designed and optimized with arcshapes and SMC materials, and with rectangles and laminated steel. The structure for the two machines is shown in Fig. 7, and the design parameters and outputs are given in Table 2 . 


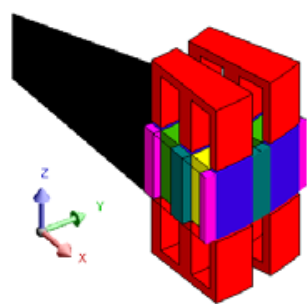

(a) Design with arc shapes

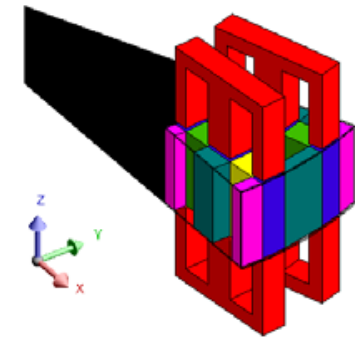

(b) Design with no arc shape
Figure 7: Isometric of view of two design structure of E-core AFM.

The machine with arc-shapes provides a better magnetic circuit by better utilization of the area. The thinner thickness in the outer pole enables the arc-shaped designs to reduce the copper weight considerably compared to designs with no arcs. Thus, a higher torque density can be achieved. The machine with no-arc still produces a high torque density and has the added benefit of being simpler in construction. The pole-to-pole leakage is also lower in machine with no-arcs that helps achieve a higher power factor.

TABLE 2: DESIGN COMPARISONS WITH ARC AND WITHOUT ARC SHAPES

\begin{tabular}{|c|c|c|}
\hline Parameter & $\begin{array}{l}\text { Machine with arc } \\
\text { shapes }\end{array}$ & $\begin{array}{l}\text { Machine without arc } \\
\text { shapes }\end{array}$ \\
\hline $\begin{array}{l}\text { Rotor/ Stator } \\
\text { material }\end{array}$ & $\begin{array}{ll}\text { SMC } & \text { Somaloy- } \\
700 & \end{array}$ & $\begin{array}{ll}\text { Laminated } & \text { Steel } \\
\text { M800 65A } & \end{array}$ \\
\hline Magnet type & Ferrite $(\mathrm{Br}=0.4 \mathrm{~T})$ & Ferrite $(\mathrm{Br}=0.4 \mathrm{~T})$ \\
\hline Machine Weight & $6.81 \mathrm{~kg}$ & $8.6 \mathrm{~kg}$ \\
\hline Magnet weight & $1.36 \mathrm{~kg}$ & $1.46 \mathrm{~kg}$ \\
\hline Coil weight & $2.57 \mathrm{~kg}$ & $4.05 \mathrm{~kg}$ \\
\hline Torque output & $26.425 \mathrm{Nm}$ & $28.23 \mathrm{Nm}$ \\
\hline Torque Density & $3.88 \mathrm{Nm} / \mathrm{kg}$ & $3.28 \mathrm{Nm} / \mathrm{Kg}$ \\
\hline Efficiency & $90.9 \%$ & $88.23 \%$ \\
\hline Power Factor & 0.638 & 0.676 \\
\hline
\end{tabular}

The next material of interest is the magnet. Generally three classes of magnets that are used for electric motors: Alnicos, ferrites and rare earth magnets. The characteristics of the three classes of magnets are shown in Fig. 6b. Performance of the case study machine with no-arc and different PM materials are presented in Table 3. The tests were conducted with the same number of turns, phase current and zero advance angle.

It is observed that the use of leakage reduction magnets help improve power factor and torque density when using ferrite and NdFeB magnets. The performances of Alnico magnets are poor due to its low coercive force. The motor needs to be redesigned with higher magnet thickness to have a better performance with Alnico magnets. The use of rare earth magnets improves the performance of the machine significantly. For the same magnet volume, the rare earth magnets would have a higher mass due to higher mass density. The torque with rare earth is 2 times more and the power factor is $34 \%$ higher compared to those with ferrites. This would allow a further downscaling of the machine.
However, rare earth magnets are considerably more expense than Alnico or ferrites.

TABle 3: PeRformanCE OF CASE STUdy E-CORE MACHINE WITH NOARCS WITH DIFFERENT MAGNETS

\begin{tabular}{llllll}
\hline \hline $\begin{array}{l}\text { Magnet } \\
\text { type }\end{array}$ & $\begin{array}{l}\text { Leakage } \\
\text { reduction } \\
\text { magnet }\end{array}$ & $\begin{array}{l}\text { Magnet } \\
\text { weight } \\
(\mathrm{kg})\end{array}$ & $\begin{array}{l}\text { Torque } \\
(\mathrm{Nm})\end{array}$ & $\begin{array}{l}\text { Torque } \\
\text { density } \\
(\mathrm{Nm} / \mathrm{kg})\end{array}$ & $\begin{array}{l}\text { Power } \\
\text { factor }\end{array}$ \\
\hline \hline Alnico & Yes & 2.18 & 13.78 & 1.48 & 0.33 \\
Alnico & No & 0.93 & 13.17 & 1.63 & 0.35 \\
Ferrite & Yes & 1.46 & 27.92 & 3.25 & 0.63 \\
Ferrite & No & 0.63 & 13.46 & 1.73 & 0.39 \\
NdFeB & Yes & 2.53 & 55.73 & 5.78 & 0.84 \\
NdFeB & No & 1.08 & 37.73 & 4.35 & 0.76 \\
\hline \hline
\end{tabular}

\section{Phase and pole number selection}

The combination of the stator and rotor poles determines the number of phases in the proposed machine. Single-phase machines could be constructed where the number of the rotor and stator poles is kept the same. Higher pole numbers result in an increased electrical loading as given in Eqn. 6. Figure 8 shows the effect of changing poles on torque density and power with the same current density and design ratios with respect to $P_{w}$ and core length. As the number of pole increases, the torque density improves but starts decreasing once the poles saturate which occurred around 42 poles in this machine. The power factor also improves but starts decreasing due to increased leakage caused by fringing fluxes at high pole numbers.

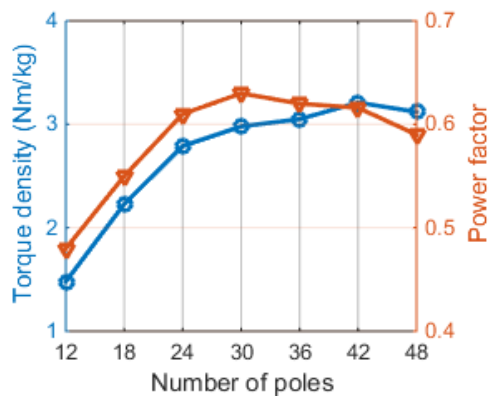

Figure 8: Effect of pole numbers in a single phase E-core AFM.

The $P_{w}$ is crucial in the determination of the machines performance. Large $P_{w}$ lead to increased magnetic loading at the cost of lower electric loading due to smaller winding area. A trade-off between magnetic loading and electric loading needs to be established for attaining the highest torque density and power factor. In this case, study, a ratio of 0.53 between the $P_{w}$ and $P_{p}$ offered the best performance for designs with and without arcs. The ratio was the same for different pole numbers.

Multi-phase versions of the proposed AFM can be achieved in two ways. One way is to stack multiple single-phase modules as proposed in [13]. The second approach is to have an uneven number of rotor and stator poles. The winding will be short-pitched. The numbers of stator and rotor poles can be obtained from: 


$$
\begin{gathered}
N_{s}=2 N_{p h} N_{r e p} \\
N_{r}=N_{s}-2 N_{r e p}
\end{gathered}
$$

where, $N_{s}$ is the number of stator pole, $N_{p h}$ is the number of phases, $N_{r e p}$ is the number of repetitions, and $N_{r}$ is the number of rotor poles.

\section{E. Mechanical Construction}

The modular rotor cores and magnets are cubes, which makes the cutting and stacking simpler. The rotor cores are made of lamination steel (M19) stacked together. The inner and outer rotor core is of the same dimension. Therefore, only two lamination cuts are required for the rotor. The rotor cores are attached to a non-magnetic disk. The rotor cores and the magnets which are sandwiched in between are held together using structural adhesives. A non-magnetic stainless steel belt could also be strapped around the rotor to add further structural integrity.

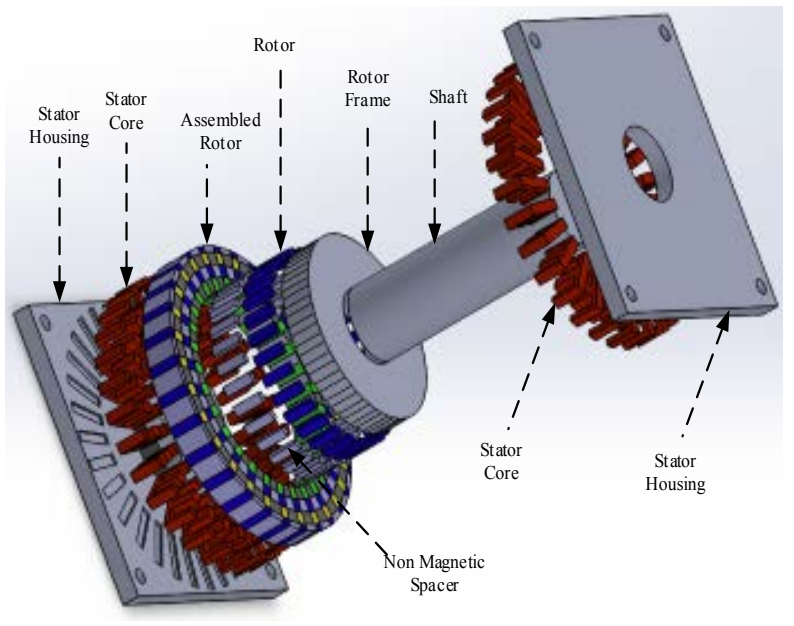

Figure 9: Exploded view of the complete motor assembly.

The E-core is also manufactured by stacking lamination steel (M19). The stator cores are attached to a supporting plate at the two ends as shown in the exploded view of the complete motor in Fig. 9. In the proposed design, the top and bottom stator cores are aligned with each other. The windings in the proposed machine are pole windings, which are wound across each leg of the E-core. Therefore, simple modular windings using bobbins can be used making the winding assembly and production automated. The exposure of the stator windings to the air also help in cooling.

\section{EleCtromagnetic ANALYSIS OF E-CORE AFM}

Electromagnetic analysis using 3D finite elements (FE) on Flux 3D was carried out on a single phase 30-pole E-Core AFM with no arc. The dimensions of the machine are given in Table 1. The FE analysis gives the magnetic flux density and flux paths in different parts of the machine. The flux lines of a single pole using 2D FEA is shown in Fig. 10; leakage flux within the slots is shown. The direction of flux paths in one pole pair of the machine is shown in Fig 11.
The flux path of one pole is shown in Fig. $11 \mathrm{~b}$ and matches with the concept presented in Fig 1.

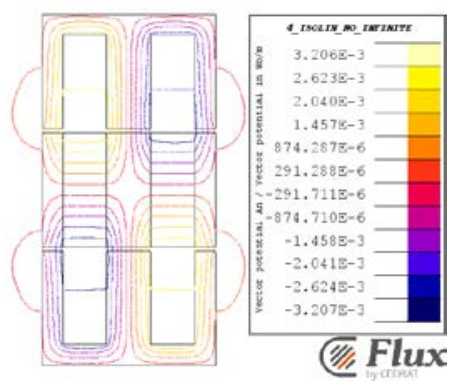

Figure 10: Flux lines of one pole with 2D FEA.

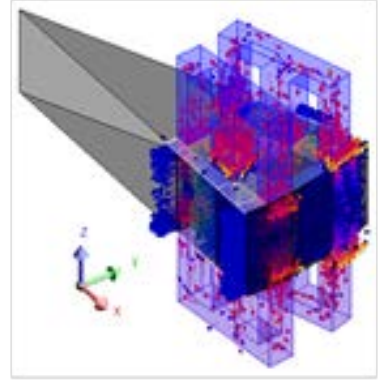

(a) Flux path in 1 pole pair

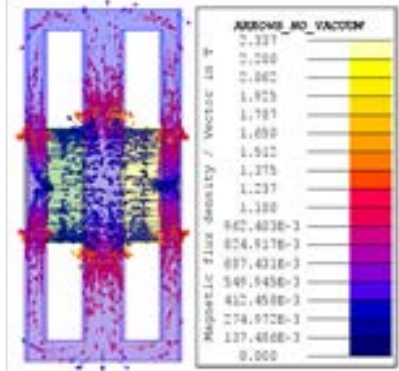

(b)Flux path in one pole.
Figure 11: Flux path of single phase E-core AFM at aligned position.

The flux densities at the aligned position with no-load is shown in Fig 12. The edges near the air gap have a higher flux density of around $1.7 \mathrm{~T}$. The flux density in the stator teeth is around $1.3 \mathrm{~T}$. The flux density is higher in the central teeth. The rotor has a relatively low flux density with highest flux density of $1.3 \mathrm{~T}$ near the air gap.

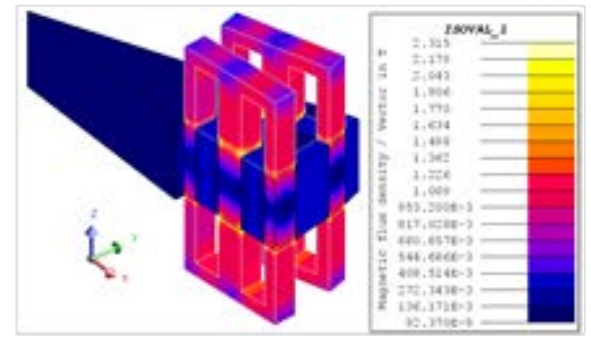

Figure 12: Flux density at aligned position.

The air gap flux density from the inner airgap to the outer stator is shown in Fig. 13a. The density is higher in the central airgap due to leakage and different size of leakage reduction magnets. The airgap flux density from one pole to another along the length of the pole-pitch in the central stator length is shown in Fig. 13(b). It is observed that a high flux density of $0.80 \mathrm{~T}$ peak was achieved at the center of middle leg of the E-core stator during aligned position. This demonstrates that it is possible to have a high airgap flux density through flux concentration when using ferrite magnets with low remnant flux density. 


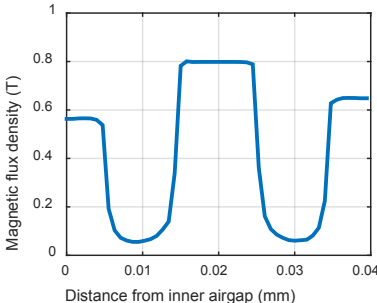

(a) Flux density from inner to outer stator teeth.

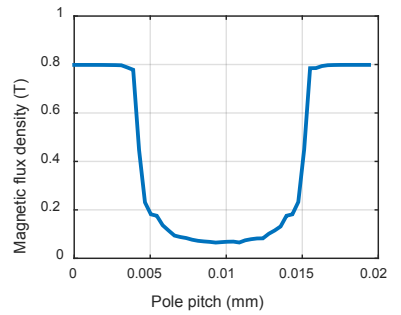

(b) Flux density from one pole to another.
Figure 13: Air gap flux density at aligned position.

The flux linkage of the top stator with no load at $400 \mathrm{rpm}$ is shown in Fig 14(a). A near sinusoidal flux linkage is observed. The back-emf with no load at $400 \mathrm{rpm}$ is shown in Fig. 14(b), which is near sinusoidal, but with some harmonic components.

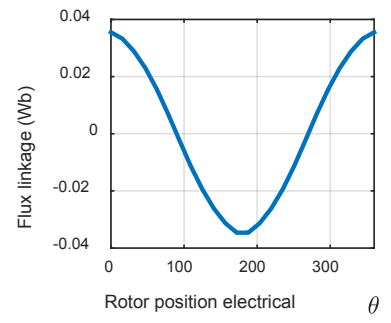

(a) Flux linkage of coil

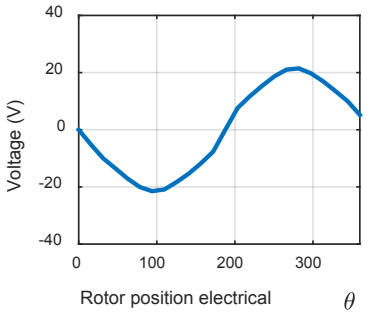

(b) Back-emf voltage
Figure 14: No load characteristic of top stator.

The effect of armature MMF applied through the windings is shown in Fig. 15(a). The output torque increases as the ampere-turns are increased by increasing the current. The machine also produces some reluctance torque due to the salient nature of the rotor; this is shown in Fig 15(b). It can be observed that as the phase angle is advanced there is an increase in torque. A certain optimum phase angle for max torque-per-ampere exists.

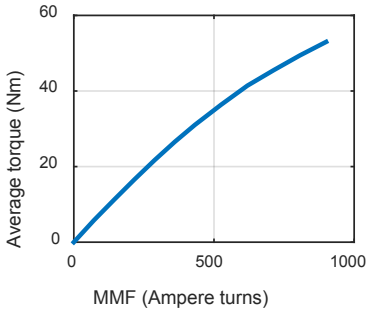

(a) Effect of armature MMF

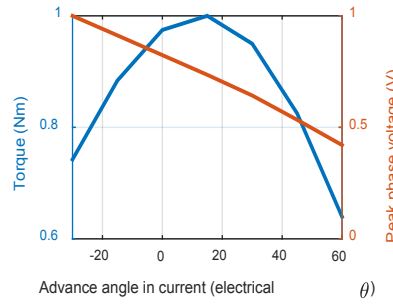

(b) Effect of phase advance Figure 15: Effect of current in windings.

A three-phase E-core AFM with a 30-20 pole combination with specifications the same as the case study machine is also designed. A top view of the machine illustrating the windings is shown in Fig 16(a). An isometric view illustrating the flux density at different parts of the machine is shown in Fig 16(b).

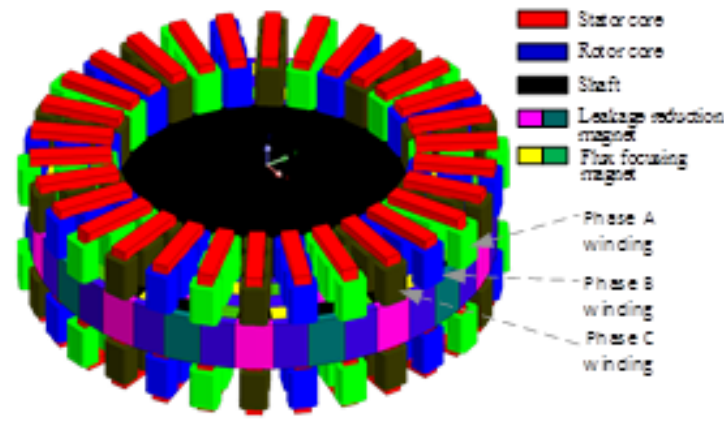

(a) $3 \mathrm{D}$ view of the proposed machine

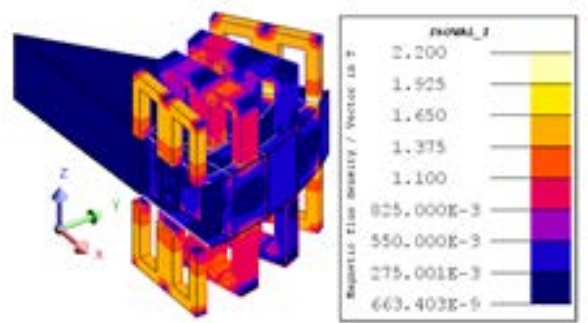

(b) Isometric view of the flux density at max armature current.

Figure 16: FEA model and flux density distribution of three phase E-AFM.

The variation of the airgap flux density at no load at the center of one stator pole as the machine rotates is shown in Fig. 17(a). The back-emf of the three-phase machine has higher third and fifth order harmonics as shown in Fig 17(b).

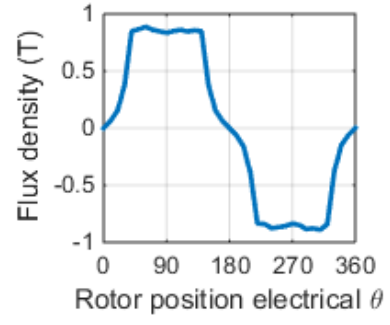

(a) Air gap flux density

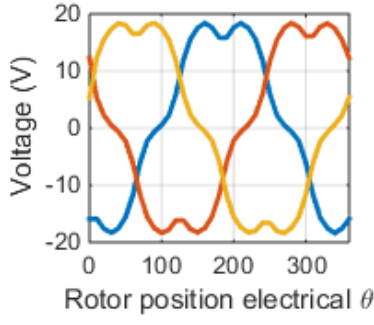

(b) Back-EMF waveform
Figure 17: Air gap flux density and back-emf waveform of three phase E-Core AFM.

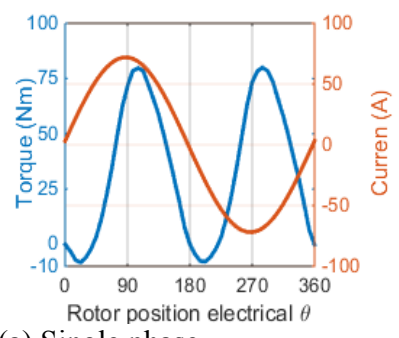

(a) Single phase

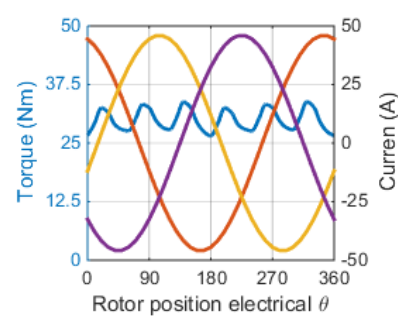

(b) Three phase
Figure 18: Torque and current waveforms at rated speed and current. 
The torque and current waveforms of the single and three phase E-core AFM at the rated speed of $400 \mathrm{rpm}$ is shown in Fig. 18. The single-phase machine exhibits a much higher torque ripple compared to the three-phase machine as expected. The three-phase machine also exhibits some torque ripple due to the presence of higher order harmonics in the back-emf.

\section{COMPARISION With DifFERENT MACHINES}

A comparison between radial surface PM machines and the proposed single-phase (M I) and three-phase (M II) E-core AFM is presented in this section. The design guidelines for the three RFM (Fig. 19) in the comparison are:

- All machines have the same outer diameter of $224 \mathrm{~mm}$. This allows for a better comparison of volume as discussed in [19].

- A current density between 5 and $6 \mathrm{~A} / \mathrm{mm}^{2}$ is maintained at peak conditions.

- The combination of number of turns and currents is set to utilize a maximum DC bus of $48 \mathrm{~V}$ at the rated speed of $400 \mathrm{rpm}$.

- The same lamination material and thickness is used.

- At rated condition, the peak flux density is maintained below $2 \mathrm{~T}$.

- The same magnet material is used.
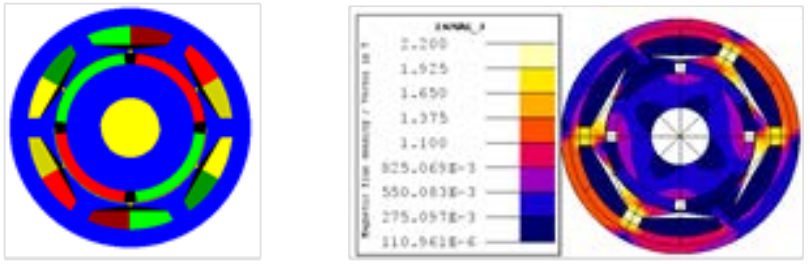

(a) 6-4 Ferrite surface PMSM with concentrated winding.
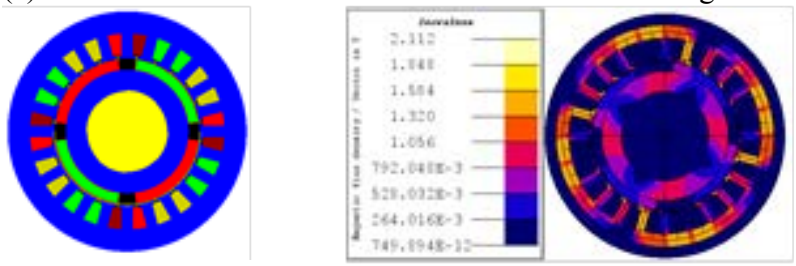

(a) 24-4 Ferrite surface PMSM with distributed winding.
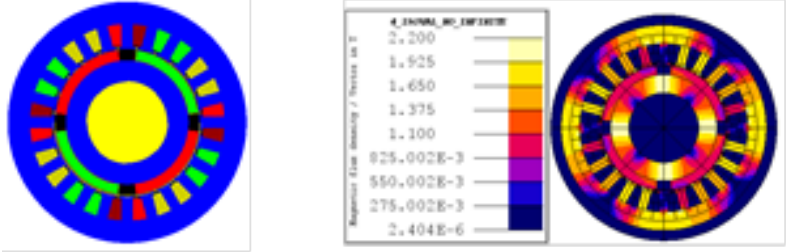

(a) 24-4 NdFeB surface PMSM with distributed winding.

Figure 19: Cross section and flux density distribution of comparison machines.

A 6-4 surface mounted ferrite PM machine with concentrated windings (M III) and a 24-4 surface mounted ferrite PM synchronous machine (SMPMSM) with distributed windings (M IV) is designed. A SMPMSM with
$\mathrm{NdFeB}$ magnet (M V) is also compared with the proposed machine. The machines were designed with the mentioned restrictions using the method proposed in [22]. The optimization procedure is based on particle swarm optimization of an analytical model of the surface PM machine. The machines are compared with respect to efficiency, volume, active weight of materials, losses and power factor. The cross section and flux density at maximum armature current for the designed RFMs are presented in Fig. 19. The key design and performance parameters of the machines are given in Table 4.

TABLE 4: KEY PARAMETERS IN COMPARISONS OF DIFFERENT MACHINES

\begin{tabular}{cccccc}
\hline \hline Performance & M I & M II & M III & M IV & M V \\
\hline \hline Speed (rpm) & 400 & 400 & 400 & 400 & 400 \\
Remnant Flux density Br (T) & 0.4 & 0.4 & 0.4 & 0.4 & 1.1 \\
Air gap (mm) & 1 & 1 & 0.7 & 0.7 & 0.7 \\
Outer radius (mm) & 112.5 & 112.5 & 112.5 & 112.5 & 112.5 \\
Stack length (mm) & 80 & 84.8 & 90 & 82 & 45 \\
Current density (A/mm2) & 5.41 & 5.51 & 5.34 & 5.4 & 5.1 \\
Torque (Nm) & 28.23 & 28.2 & 28.29 & 29 & 29.34 \\
Vrms (V) & 17.19 & 8.66 & 19.4 & 19.31 & 20.32 \\
Irms (A) & 50.91 & 26.87 & 31.82 & 28.28 & 22.64 \\
Power mechanical (W) & 1182 & 1181 & 1185 & 1214 & 1229 \\
Core Loss (W) & 20 & 15.9 & 10.6 & 8.68 & 12.48 \\
Copper loss (W) & 135 & 154 & 95 & 120 & 64 \\
Efficiency (\%) & 88.23 & 87.3 & 91.75 & 90.36 & 94 \\
Power factor & 0.676 & 0.846 & 0.64 & 0.74 & 0.9 \\
Weight Magnet (kg) & 1.46 & 1.517 & 1.66 & 1.52 & 0.756 \\
Weight Coil (kg) & 4.05 & 4.01 & 3.6 & 2.4 & 1.56 \\
Steel Weight (kg) & 3.09 & 4.16 & 18.28 & 12.8 & 8.256 \\
Total Weight (kg) & 8.6 & 9.68 & 23.54 & 16.72 & 10.57 \\
Torque Density (Nm/kg) & 3.28 & 2.91 & 1.2 & 1.73 & 2.78 \\
Volume (l) & 3.18 & 3.37 & 3.58 & 3.26 & 1.79 \\
Power density (kW/l) & 0.37 & 0.35 & 0.33 & 0.37 & 0.68 \\
\hline \hline
\end{tabular}

From the comparison among the four machines, it can be observed that the E-core single-phase machine attains the highest torque density. It is almost 2 to 2.5 times that of ferrite RFMs. The three-phase E-core AFM also achieves a torque density improvement of 2 times compared to ferrite RFMs. The improvement in the torque density is due to a reduction of the active weight of the machine. The active weight of the E-core machines is comparatively smaller due to shorter magnetic flux paths. However, the weight of the coils is higher in the E-core machines, which result in higher copper loss. In addition, the core losses are higher due to a higher fundamental frequency. Thus, the efficiency of the Ecore machine is slightly lower. The difference in the rotational frequency is due to the nature of AFMs and RFMs. AFMs typically have a higher number of poles compared to RFMs. The power factor is lower in the single 
phase E-core AFM. A slightly higher power factor was observed in the three-phase AFM. The SMPM with distributed windings demonstrates the highest power factor. The AFM also demonstrated a slightly higher torque density compared to NdFeB based SMPM. However, the efficiency is lower by a large margin. The comparison demonstrates the benefits of the proposed AFM in terms of higher torque density. The power factor and efficiency is also comparable to ferrite SMPMSMs, slightly lower than $\mathrm{NdFeB}$ SMPMSMs.

\section{CONCLUSIONS}

The paper presents the design of a novel E-core modular axial flux machine. The machine has a double-sided stator configuration with flux concentrating ferrite magnets. The flux concentrating principle allows the use of low cost ferrite magnets while maintaining a high air gap flux density. E-core stators with pole windings are proposed to ensure maximum core and magnet utilization. The proposed machine also has a modular structure making it easier to manufacture. An analytical sizing method for machine is presented using which single-phase and three-phase variants of the proposed machine is presented for the case study application. The proposed machine is compared with ferrite and rare earth RFMs. It is observed that the proposed machine exhibits a high torque density with similar power factor and efficiencies in comparison to RFMs. The comparison illustrates the promise this machine holds as an alternate topology to rare earth based machines.

\section{REFERENCES}

[1] I. Boldea, L.N. Tutelea, L. Parsa, D. Dorrell, "Automotive Electric Propulsion Systems with Reduced or No Permanent Magnets: An Overview," IEEE Trans. Ind. Electron., on vol. 61, no.10, pp.5696,5711, Oct. 2014.

[2] A. Mahmoudi, S. Kahourzade, N. A. Rahim, W. P. Hew, and M. N. Uddin, "Design and prototyping of an optimised axialflux permanent-magnet synchronous machine," IET Electr. Power Appl., vol. 7, no. 5, pp. 338-349, 2013.

[3] S. Huang, J.Luo, F. Leonardi, T.A. Lipo, "A comparison of power density for axial flux machines based on general purpose sizing equations,"IEEE Trans. Energy Conv. , vol.14, no.2, pp.185,192, Jun 1999.

[4] K.M. Rahman, N.R. Patel, T.G Ward, J.M. Nagashima, F. Caricchi, F. Crescimbini, F., "Application of Direct-Drive Wheel Motor for Fuel Cell Electric and Hybrid Electric Vehicle Propulsion System," IEEE Trans. Ind. Appl.,, vol.42, no.5, pp.1185,1192, Sept.-Oct. 2006.

[5] J. T. Chen, Z. Q. Zhu, S. Iwasaki, and R. P. Deodhar, "A novel E-core switched-flux PM brushless AC machine," IEEE Trans. Ind. Appl., vol. 47, no. 4, pp. 1273-1282, 2011.

[6] Z. Q. Zhu, J. T. Chen, D. Howe, S. Iwasaki, and R. Deodhar, "Analysis of a novel multi-tooth flux-switching PM brushless AC machine for high torque direct-drive applications," IEEE Trans. Magn., vol. 44, no. 11, pp. 4313-4316, Nov. 2008.

[7] Z. Q. Zhu and J. T. Chen, "Advanced flux-switching permanent magnet brushless machines," IEEE Trans. Magn., vol. 46, no. 6, pp. 1447-1453, 2010.
[8] C. Lee and R. Krishnan, "New designs of a two-phase E-core switched reluctance machine by optimizing the magnetic structure for a specific application: Concept, design, and analysis," Conf. Rec. - IAS Annu. Meet. (IEEE Ind. Appl. Soc., vol. 45, no. 5, pp. 1804-1814, 2008.

[9] A. S. Thomas, Z. Q. Zhu, and L. J. Wu, "Novel modular-rotor switched-flux permanent magnet machines," IEEE Trans. Ind. Appl., vol. 48, no. 6, pp. 2249-2258, 2012.

[10] Z. Chen and E. Spooner, "A modular, permanent-magnet generator for variable speed wind turbines", in Proc. 1995 IEE Conf. Elec. Mach. And Drives, pp. 453-457.

[11] E. Spooner and A. Williamson, "Modular, permanent-magnet wind-turbine generators", in Proc. 1996 IEEE Conf. Ind. Appl., Vol. 1, pp. 497-502. 1996.

[12] E. Spooner, A.C. Williamson and G. Catto, "Modular design of permanent-magnet generators for wind turbines", IEE Proc.-Electr. Power Appl., Vol. 143, No. 5, pp. 388- 395, September 1996.

[13] E. Muljadi, C.P. Butterfield, Y.H. Wan, "Axial-flux modular permanent-magnet generator with a toroidal winding for wind-turbine applications," IEEE Trans. Ind. Appl., vol.35, no.4, pp.831,836, Jul/Aug 1999.

[14] P. O. Rasmussen, G. Runólfsson, T. Á. Thorsdóttir, U. Jakobsen, and A. H. Pedersen, "E-core transverse flux machine with integrated fault detection system," 2011 Int. Conf. Electr. Mach. Syst. ICEMS 2011, 2011.

[15] C. G. Turker and F. E. Kuyumcu, "Determining of the magnetic characteristics of the E-core Transverse Flux Machine based on neural network," 2011 Int. Symp. Innov. Intell. Syst. Appl., pp. 217-222, 2011.

[16] G. Henneberger, M. Bork, "Development of a new transverse flux motor," IEE Colloquium on New Top. for Permanent Magnet Machines, vol., no., pp.1/1,1/6, 18 Jun 1997.

[17] Hae-Joong Kim; Doo-Young Kim; Jung-Pyo Hong, "Structure of Concentrated-Flux-Type Interior PermanentMagnet Synchronous Motors Using Ferrite Permanent Magnets," IEEE Trans. Magn., vol.50, no.11, pp.1,4, Nov. 2014

[18] W.M. Arshad, T. Bäckström and C. Sadarangani, "Analytical design and analysis procedure for a transverse flux machine", Proc. IEEE Conf. Elec. Mach. and Drives, pp. 115-121. 2001.

[19] S. Huang, J. Luo, F. Leonardi, and T. a. Lipo, "A comparison of power density for axial flux machines based on general purpose sizing equations," IEEE Trans. Energy Convers., vol. 14, no. 2, pp. 185-192, 1999.

[20] P. Campbell, "Principles of a permanent-magnet axial-field d.c. machine," Electrical Engineers, Proceedings of the Institution of, vol.121, no.12, pp.1489,1494, December 1974.

[21] F. Caricchi, F. Crescimbini, E. Fedeli, and G. Noioa, "Design and construction of a wheel-directly-coupled axial-flux PM motor prototype for EVs," Proc. 1994 IEEE Ind. Appl. Soc. Annu. Meet, 1994.

[22] Y. Duan, "Method for design and optimization of surface mount permanent magnet machines and induction machines," Electrical Engineering, Georgia Institute of Technology, Atlanta, GA, 2010. 